\title{
The Effects of Culture of Muslim Students on Their Reading Comprehension
}

\author{
Seyedeh Sara Jafari", Hajar Aghaei \\ Department of foreign languages, Abadeh branch, Islamic Azad University, Abadeh, Iran \\ *Corresponding Authorl: a.jafari1@yahoo.com
}

Copyright (C) 2013 Horizon Research Publishing All rights reserved.

\begin{abstract}
This research studies whether cultural schema has an influence on reading comprehension and whether using a set of reading activities make up for the lack of cultural familiarity. 80 Turkish/Persian language students of pre-university participated in the cross-cultural study.Post-Hoc Scheffe and one-way ANOVA test were used in the study. We found that the Turkish language groups recalled the material dealing with their own cultural background better and more overall than their counterparts, i.e. the cultural-specific schema embodied in the English version of the Turkish short story "Aal" by Mohammad BahmanBeigi contributed to the Turkish language participants to have significantly better understanding of the text, while both groups were reading in their foreign language, and the use of activities facilitated for better literal understanding of the text. This way, it emphasizes a strong impact of cultural familiarity on comprehension.
\end{abstract}

Keywords Schema Theory, Culture, Reading Comprehension

\section{Introduction}

Research on the psychological processes involved in comprehension clearly shows that what we understand of something is a function of our past experiences, our background knowledge, or what are something more technically called our schema (Carrell\& Wallace, 1983; Rumerhart\&Ortony, 1977). According to schema-theorists, dating from as far back as Immanuel Kant 1781, and Sir Frederick Bartlett in 1932, up to more contemporary schema theorists like David Rumelhart in 1980, we comprehend something only when we can relate it to something we already know (Yang, 2008; McVee, Dunsmore, \&Gavelek, 2005; Ajide, 2003; Satio, 2000)

Reading comprehension has been regarded as interplay of text-based and knowledge based processes of readers. Since comprehension is a gradual process which involves the coalescence of information from disparate parts of text, the construction of text meaning necessitates a hybrid of text information which is explicitly stated in the text in addition to relevant knowledge stored in long-term memory (Koda, 2005).

Readers use a combination of both literal and inferential comprehension during reading. The former is based on lexical access and syntactic parsing while the latter is based on higher level cognitive processes including text base of comprehension, which is about understanding what the text says and the situation model of interpretation which is about understanding what the text is about(Alptekin,2006:494). In literal comprehension, lexical access necessitates a high degree of text-dependence in which words in atext are assigned meaning, whereas in syntactic parsing words or constituents come together to form semantic propositions. On the other hand, inferential comprehension requires the combination of successive propositions to make a meaningful whole by using reasoning and drawing conclusions about the relationships between or among bits of information that are not explicitly stated within the text. Inferences require reading beyond the literal meaning of explicitly stated text elements in the text, including prior knowledge and monitoring comprehension to help better comprehension outcomes. That is, prior knowledge activation should be brought to the text to resolve relational gaps stemming from inferences (Brantmeier, 2004:1-7).

\section{Schema Theory and Reading Comprehension}

It is stated that the interpretations of the readers vary according to their background knowledge in that a major task in discourse processing lies in discriminating thematic information from peripheral information (Singer, 1994:479). The influence of background knowledge on inferences is indisputable since inferences are driven by schemas (Ketchum, 2006:22). There have been many discussions on schema theory. A schema is defined as an abstract knowledge structure (Anderson \& Pearson, 1984:306). The theory is closely associated with how readers combine their 
previous knowledge with the text (Alptekin, 2006: 494; Carrell, 1983a: 183, 1983b:81).In cognitive sciences, a schema theory is basically "a theory about knowledge" (Rumelhart, 1980: 33). Sir Frederick Charles Bartlett (1886 -1969) was credited as the first psychologist who used the term in its cognitive sense in the 1920s (Brewer, 2000: 69-89). Schema theories study how knowledge is represented and how their representation facilitates the use of knowledge. Schemas are viewed by Rumelhart (1980) as building blocks of cognition. Conversely, schemas are abstract cognitive constructs where knowledge is processed, stored and activated.

\section{Cultural Schema}

Schematic representations of generic concepts distributed among cultural members, are cultural schemas, which are interchangeably called cultural models. Cultural schemas are used by cognitivists to study the foundations upon which people of one culture are able to identify each other as cultural members and are able to communicate successfully with each other (Holland \& Quinn, 1987). In other words, cultural schemas, though subject to ongoing modification, have the property of being stable and consistent on the whole (Strauss \& Quinn, 1997: 33-44). Anthropologist Gary Palmer (1996) posits that cultural schemas are derived from social structure, salient rituals and a host of other cultural phenomena. Moreover cultural schemas can be instantiated in various cultural artefacts, such as painting, rituals and narratives (Sharifian, 2003:187-207).Idioms, proverbs or popular sayings are another instantiation of cultural schemas as they packaged with cultural wisdoms and express culturally constituted understandings.

\section{Reading Activities}

Many studies have been carried out to emphasize the effect of cultural schema and background knowledge on reading comprehension, yet studies which examine whether the use of reading activities can make up for the absence of cultural knowledge are not much.

Erten\&Razı (2009), Following Alptekin's ideas, carried out a study with an aim to extend Alptekin's work to achieve a better understanding of his work. They added reading activities to the methodology to see if reading activities such as pre-reading, brainstorming, pre-questioning, scanning, skimming, clarifying, reciprocal teaching, inferring, thinking aloud, asking and answering questions can compensate for the absence of cultural schema. That is, they hypothesized that reading activities will affect readers' literal understanding positively. The results of their study revealed that activities contributed to the comprehension of the text, yet the effect of background knowledge remained intact specifying a strong effect of cultural schemaon comprehension.

\section{Aim of the Research}

By now several empirical studies have been carried out showing the effect of schema, or background knowledge, on language comprehension (Carrell 1983a, 1983b, 1983c, 1981a, 1981b; Hudson, 1982; Johnson 1981, 1982; Kintsch\& Greene 1978; Thorndkey 1977; Anderson, Reynolds, Schallert\& Goetz 1977,Mandler\& Johnson 1977; Bransford\& Johnson, 1973),supporting the previous studies with the inclusion of reading activities would be worth replicating to have a better account of the issue with the use of a similar design in a different context with different groups. Therefore the aim of this study is to find out to what extent both cultural knowledge and reading activities are effective on the comprehension of short story. The research questions and the hypotheses of the study are as follows:

Research Question-(RQ1).Does cultural schema of the participants have an effect on their reading comprehension?

Research Question- (RQ2). Can reading activities compensate for the absence of cultural schema?

Hypotheses- (H1). Cultural schema will have a significant effect on reading comprehension.

Hypotheses- (H2).Although reading activities contribute to comprehension, the impact of cultural schema will remain a significant factor.

\section{Method}

The study was carried out in 2012educational year. The English course was regarded appropriate for the study since the program contains reading classes where the teachers make use of many diverse short stories and literary works.

\subsection{Participants}

The study has been conducted in Arjan area, located in Fars, 35 kilometers to Shiraz. 80 Turkish/Persian language students of pre-university took part in the research. The ages of the participants ranged from 18-19. They all shared similar educational backgrounds. In assigning participants, their GPAs at the end of their fourth year of high school were regarded to form the research design. In calculating their GPAs, only the English courses were considered. In order to achieve this, marks gained by each student from courses were multiplied by the number of credits of the course and then the sum of multiplied course loadings was divided by the total number of credits earned by the participants. The students who had failed any English courses were ignored as they were thought as those who cannot meet the minimum language requirements to be included in the study. So, English language competencies of the control and experimental groups were considered to be equivalent in terms of their proficiency levels. 
At last, students from each range of GPAs were assigned to four diverse groups. This

Placement was done to create homogeneous groups in which participants were believed to display similar scores in accordance with their similar GPAs. With this in mind, four treatment groups were labelled as Treatment 1 (Persian language participants' text with no activities- PNA), Treatment 2 (Persian language participants 'text with activity- PWA), Treatment 3(Turkish language participants' text with no activity- TNA), and Treatment 4 (Turkish language participants' text with activity- TWA). The participants in first treatment group (PNA) read the text without the use of reading activities, whereas the second treatment group of participants (PWA) was supposed to read the text with the accompaniment of pre-reading, while reading and post reading activities which were thought to contribute to the comprehension of readers. The third treatment group of participants (TNA) was required to read the text without the use of reading activities and finally the fourth treatment group of participants (TWA) were given the version of the text with reading activities.

Mean GPA values for each treatment group are given in Table 1.

Table 1a. Mean GPA values for each treatment group

\begin{tabular}{|c|c|c|c|}
\hline $\begin{array}{c}\text { Name of the } \\
\text { group }\end{array}$ & $\mathrm{N}$ & Mean & Std. Deviation \\
\hline & & & \\
\hline PNA & 20 & 19.50 & 0.51 \\
\hline PWA & 20 & 19.55 & 0.51 \\
\hline TNA & 20 & 19.55 & 0.51 \\
\hline TWA & 20 & 19.20 & 0.41 \\
\hline Total & 80 & 19.45 & 0.50 \\
\hline
\end{tabular}

Table 1b. Test of Homogeneity of Variances

\begin{tabular}{|c|c|c|c|}
\hline $\begin{array}{c}\text { Levene } \\
\text { Statistic }\end{array}$ & df1 & df2 & Sig. \\
\hline 9.487 & 3 & 76 & .000 \\
\hline
\end{tabular}

Table 1c. ANOVA (GPA Homogeneity)

\begin{tabular}{|c|c|c|c|c|c|}
\hline Condition & $\begin{array}{c}\text { Sum of } \\
\text { Squares }\end{array}$ & $\mathrm{df}$ & $\begin{array}{c}\text { Mean } \\
\text { Square }\end{array}$ & $\mathrm{F}$ & Sig. \\
\hline $\begin{array}{c}\text { Between } \\
\text { Groups }\end{array}$ & 1.700 & 3 & .567 & 2.379 & .076 \\
\hline $\begin{array}{c}\text { Within } \\
\text { Groups }\end{array}$ & 18.100 & 76 & .238 & & \\
\hline Total & 19.800 & 79 & & & \\
\hline
\end{tabular}

An analysis of variance revealed that there were no significant differences among the treatment groups, $\mathrm{F}=2.379$, $\mathrm{P}>.05,(\mathrm{P}=.076)$, indicating a reasonable homogeneity of these groups.

\subsection{Instruments}

\section{a. The reading text}

The short story 'Aal' by Mohammad BahmanBeigi which was first published in1989, was chosen for the text. The short story tells us a day of a family ofGhashghai tribe, a great tribe to which the Turkish language participants belonged. A cultural schema "Aal" was believed to be a kind of jinn which was being fed with the liver of the woman who was in labor. The woman died when her relatives and midwives were trying to save her by slapping in the face, scaring her with forcing horse whinny, shooting into the sky and feeding her bizarre unsanitary things to evoke the jinn, since poor visibility and severe bleeding and fainting of the mother were expected to be related to "Aal "who penetrated to her soul. Due to the purposes of research the story was translated from Persian to English. Care was taken while translating the names of the characters were not substituted with English names. All the names of things had to be logical in readers' minds so as to activate their schemas about the Ghashghai tribe.

\section{b. Reading Test}

A post-test which was recall-type in nature, was administered, when participants completed the reading session. Three different elicitation techniques constituted the post-test. The first set of ten questions contain True/False/Not Given items, whereas the second set of eight questions were related with putting some scrambled actions into correct order. Eventually, ten open-ended pen and paper type of comprehension questions were used as the last set of questions to check comprehensions of the students in all treatment groups. During the post-test period, not only the students were not permitted to refer to the reading text but also they were not permitted to use their dictionaries. Due to the fact that the students had not read the story before the experiment a pre-test was not considered.

\subsection{Procedure}

The participants in the first treatment group (PNA) read the text without activities, while the second treatment group of participants (PWA) read the text with a set of reading activities. The third treatment group of participants (TNA) read version of the text without activities and finally the fourth treatment group of participants (TWA) was given the version of the text with reading activities. Table 2 represents the procedures applied for each group of students in four different treatment groups.

The items of the post-test were piloted with 16 students who have similar educational background with the participants in the study, with GPA scores in the same range as those of the participants. The aim was to identify test items that were too difficult or too easy. Revealing that each item performed satisfactorily, the study suggested that the post-test had high Cronbach's alpha $(r=.84$ and $\mathrm{p}<.01)$, which was considered to be consistent enough to continue 
conducting the post-test post-test to the real sample.

Table 2. Procedures for each treatment group

\begin{tabular}{|c|c|c|c|}
\hline $\begin{array}{c}\text { Treatment } 1 \\
\text { (PNA) }\end{array}$ & $\begin{array}{c}\text { Treatment } 2 \\
(\mathrm{PWA})\end{array}$ & $\begin{array}{c}\text { Treatment } 3 \\
\text { (TNA) }\end{array}$ & $\begin{array}{c}\text { Treatment } 4 \\
\text { (TWA) }\end{array}$ \\
\hline $\begin{array}{c}\text { The Persian } \\
\text { language } \\
\text { participants' } \\
\text { text } \\
\text { With no } \\
\text { activities }\end{array}$ & $\begin{array}{l}\text { (The Persian } \\
\text { language } \\
\text { participants' text } \\
\text { with activities) } \\
\text { Pre-reading } \\
\text { activities: } \\
\text { Brainstorming } \\
\text { Pre-questioning } \\
\text { Reading the } \\
\text { story } \\
\text { While-reading } \\
\text { activities: } \\
\text { Scanning / } \\
\text { Skimming } \\
\text { Clarifying } \\
\text { Reciprocal } \\
\text { teaching } \\
\text { Inferring } \\
\text { Post-reading } \\
\text { activities: } \\
\text { Thinking aloud } \\
\text { Question / } \\
\text { Answer }\end{array}$ & $\begin{array}{c}\text { The Persian } \\
\text { language } \\
\text { participants' } \\
\text { text } \\
\text { With no } \\
\text { activities }\end{array}$ & $\begin{array}{l}\text { (The Persian } \\
\text { language } \\
\text { participants' text } \\
\text { with activities ) } \\
\text { Pre-reading } \\
\text { activities: } \\
\text { Brainstorming } \\
\text { Pre-questioning } \\
\text { Reading the } \\
\text { story } \\
\text { While-reading } \\
\text { activities: } \\
\text { Scanning/ } \\
\text { Skimming } \\
\text { Clarifying } \\
\text { Reciprocal } \\
\text { teaching } \\
\text { Inferring } \\
\text { Post-reading } \\
\text { activities: } \\
\text { Thinking aloud } \\
\text { Question / } \\
\text { Answer }\end{array}$ \\
\hline
\end{tabular}

Note. PNA = Persian language participants' text with no activities; $\mathrm{PWA}=$ Persian language participants 'text with activities;TNA = Turkish language participants' text with no activities; TWA= Turkish language participants' text with activities.

\section{Data Analysis}

Two independent raters marked the open-ended question part of the post-tests including students' answers. Papers were only rated for comprehension purposes ignoring grammatical mistakes to minimize the influence of any variation among the writing skills of participants.

In the post-test part where participants were asked to order some events from the story was marked according to the Weighted Marking Protocol. Such protocol has a nature of partial evaluation as the marking procedure of the protocol is based on correcting the wrong order of events provided by the students and decreasing their marks with reference to their mistakes. In this protocol students are given some marks even if they do not put all the events in the right order (Razi, 2005:15).

Marks given by two independent raters were analyzed through Pearson Correlation Coefficient Procedure. A high correlation coefficient was found among the two sets of marks $(r=.84$ and $\mathrm{p}<.01)$, which was regarded to be consistent enough to go on further statistical analysis.

Post-test scores of the participants were analyzed through the use of ANOVA to find out whether there were differences among the treatment groups according to their gained scores. After the results of ANOVArevealed that there were differences across the treatment groups, a Post-Hoc Scheffe test was used to see where the group differences happened.

\section{Results}

Table 3 indicates descriptive statistics giving the mean scores gained by each treatment group included in the study. As seen in the table, the Turkish language participants who read the short story with reading activities outscored the other groups and outperformed them with having the highest mean scores gained according to the results of post-test. The Turkish language participants who read the short story without reading activities scored higher than Persianlanguage students who read the text with and without reading activities

Table 3 reveals, there are some differences among the mean values of the groups gained in the study.

Table 4 demonstrates, statistically significant differences between groups where $p<.05$. The results of One-Way ANOVA Test point out that the mean values of the treatment groups gained in the study are not the same.

Table 3. Mean scores of groups

\begin{tabular}{|c|c|c|c|}
\hline $\begin{array}{c}\text { Treatment } \\
\text { Condition }\end{array}$ & $\mathrm{N}$ & Mean & Std. Deviation \\
\hline PNA & 20 & 13.85 & 1.87 \\
\hline PWA & 20 & 15.50 & 1.42 \\
\hline TNA & 20 & 17.35 & 1.66 \\
\hline TWA & 20 & 18.30 & 1.92 \\
\hline & 80 & 16.25 & 2.42 \\
\hline Total & 80 & \\
\hline
\end{tabular}

Note. PNA $=$ Persian language participants' text with no activities; PWA $=$ Persian language participants' text with activities; TNA = Turkish language participants' text with no activities;

TWA $=$ Turkish language participants' text with activities.

Table 4. One-Way ANOVA Test Results

\begin{tabular}{|c|c|c|c|c|c|}
\hline $\begin{array}{c}\text { Dependent } \\
\text { Variable } \\
\text { (Post-test } \\
\text { Scores) }\end{array}$ & $\begin{array}{c}\text { Sum of } \\
\text { Squares }\end{array}$ & $\mathrm{df}$ & $\begin{array}{c}\text { Mean } \\
\text { Square }\end{array}$ & $\mathrm{F}$ & Sig. \\
\hline $\begin{array}{c}\text { Between } \\
\text { Groups }\end{array}$ & 234.70 & 3 & 78.23 & 26.04 & .000 \\
\hline $\begin{array}{c}\text { Within } \\
\text { Groups }\end{array}$ & 228.30 & 76 & 3.00 & & \\
\hline Total & 463.00 & 79 & & & \\
\hline
\end{tabular}

The differences observed between different treatment conditions were statistically significant, $F=26,04, p$ $<.001(\mathrm{p}=.000)$. Group differences were examined through a post-hoc Scheffe Test. The results are illustrated in Table 5.

Table 5, showed that there are highly significant differences between the treatment groups. The first hypothesis of the study, that cultural schema has a significant effect on reading comprehension, was sufficiently supported by the between-group differences confirming that cultural schema influenced the participants' comprehension. The 
TNA group outperformed $(M=17.35)$ the PNAgroup $(M=$ $13.85)$, with a considerable effect size $(d=2.80)$. The second comparison was done between activity groups and a significant difference was found. The TWA students $(M=$ 18.30) did significantly better than the PWA students $(M=$ $15.50)$, indicating a large effect size $(d=3.50)$.

Table 5. Post-Hoc Scheffe Test (Multiple Comparisons) for the total score of the post-test

\begin{tabular}{|c|c|c|c|}
\hline \multicolumn{2}{|c|}{ Conditions } & Mean Difference & Sig. \\
\hline & & & \\
\hline \multirow[t]{3}{*}{ PNA VS. } & TWA & $-1.85(*)$ & .014 \\
\hline & TNA & $-2.80(*)$ & .000 \\
\hline & PWA & $1.65\left(^{*}\right)$ & .035 \\
\hline \multirow[t]{3}{*}{ PWA VS. } & TWA & $-3.50(*)$ & .000 \\
\hline & TNA & $-4.45(*)$ & .000 \\
\hline & PNA & $-1.65(*)$ & .035 \\
\hline \multirow[t]{3}{*}{ TNA VS. } & TWA & .95 & .397 \\
\hline & PWA & $4.45(*)$ & .000 \\
\hline & PNA & $2.80(*)$ & .000 \\
\hline \multirow[t]{3}{*}{ TWA VS. } & TNA & -.95 & .397 \\
\hline & PWA & $3.50(*)$ & .000 \\
\hline & PNA & $1.85(*)$ & .014 \\
\hline
\end{tabular}

* The mean difference is significant at the .05 level.

Note. PNA = Persian language participants' text with no activities; PWA = Persian language participants' text with activities; TNA = Turkish language participants' text with no activities;TWA $=$ Turkish language participants' text with activities. ${ }^{*} \mathrm{P}<.05$.

The second hypothesis, that although reading activities contribute to comprehension, the impact of cultural schema remains a significant factor, was also supported by the results obtained from the comparisons between the groups. Unexpectedly, although the TWA students $(M=18.30)$ performed better than the TNA students $(M=17.35)$, the difference was not found as statistically significant, with an effect size of $(d=0.95)$, implying that reading activities influenced reading comprehension of Turkish language students as it was thought to be but this effect was not found to be statistically significant. Another finding revealed that the TWA students $(M=18.30)$ also performed better than the PNA students $(M=13.85)$, with a large effect size $(d=1.85)$. However, the difference between the PWA $(M=15.50)$ and PNA students $(\mathrm{M}=13.85)$ was not statistically significant ( $d$ $=-1.65)$, implying that the activities did help students to comprehend better to a small extent. Although there was a rise in mean scores, indicating the effect of reading activities, this effect was not statistically significant.

Another difference was observed between the PWA $(M=$ 15.50) students and the TNA students $(M=17.35, d=-4.45)$ implying that Persian language participants with activities did not perform better than Turkish language participants who read the text with no activities. Indicating that even without the use of reading activities effect of Turkish background knowledge on reading comprehension remains intact, TNA students $(M=17.35)$ performed better than $\operatorname{PWA}(M=15.50)$.

\section{Discussion}

The study aimed to concentrate on the investigation of cultural schema effect on reading comprehension. It also aimed to explore whether activities can compensate for the lack of students' relevant cultural schema.

Not surprisingly, the Persian language students who read the story with or without reading activities scored lower than their Turkish language counterparts due to the fact that the Turkish language readers did not have to deal with unfamiliar names and culturally distant contextual clues. Thus, they could process new input in their short-term memory. Therefore, it would be logical to assume that Persian language students who read the text in this study had to use controlled processes which required greater effort. On the other hand, Turkish language readers used automatic processes as they were familiar with the new information.

As for the impact of reading activities on comprehension, their value in reading comprehension cannot be ignored (Erten\&Razi, 2009: 60), yet this study did not have a purpose of comparing the effectiveness of activities. Rather, it intended to explore whether the use of reading activities can make up for the absence of culturally familiar knowledge. Actually, it would not be wrong to comment that activities contributed to comprehension since pre-reading, while-reading and post reading activities contributed to these two types of participants (PWA, TWA) for better comprehension. This is in accordance with the statements byAlptekin, (2006),Alptekin, (2002); Karakas, (2002); Chambliss\& Richardson \&Torney-Purda\& Wakefield, (1998);Erten (1988); Carrell and Eisterhold (1983); Pre-reading activities enables teachers to activate readers' schemas before reading. While reading activities do also have a facilitative role on the comprehension of the short stories. Post-reading activities also aid to clarify any unclear meaning. The results of this study accord well with the results of the earlier studies by Erten\&Raz1, (2009); Anderson, Reynolds, Schallert\& Goetz 1977, since a powerful effect of cultural schema on reading comprehension has been found. The use of reading activities was found to be facilitative but its influences was limited in that activities fail to compensate for the lack of culture-specific knowledge in the texts. 


\section{Conclusion}

Regarding to the results of the study, the following conclusions can be drawn. First, cultural familiarization to the text has a significant influence on reading comprehension. In fact cultural schema has much to offer toward the understanding of the many subtleties of reading comprehension. Another conclusion of this study is that reading activities have an effect on reading comprehension and the third conclusion indicates that reading activities have an effect on reading comprehension but the impact was limited, thus they cannot make up for the absence of cultural schema.

As noted earlier, the highest score were obtained by the students who were familiar with the background knowledge of the short story. In culturally familiar texts readers can use top-down reading models due to the conviction that their relevant schemas are activated but, on the contrary, in texts which are not culturally familiar, readers cannot use top-down reading models as the background knowledge that they bring to the text is different from the writer's. Therefore, the use of familiar texts that contain culturally familiar words and expressions, with a facilitative effect, might be increased in language classes. However, care must be taken not to underestimate the importance of reading activities in comprehension.

Finally, this study did not investigate the efficiency of a single pedagogical reading activity in promoting reading comprehension. Instead, using disparate activities that cater to different types of comprehension can contribute to a fuller understanding of texts. Thus, it enables learners go beyond literal comprehension of the text.

\section{REFERENCES}

[1] Ajide, P. (2003), Schema theory-based pre-reading tasks: A neglected essential in the ESLreading class, Reading Matrix: An International Online Journal, 3(1).

[2] Alptekin, C. (2002), The effects of cultural knowledge on EFL reading comprehension, Opening plenary speech at InternationalBalkan ELT Conference. Edirne: Trakya University.

[3] Alptekin, C. (2006), Cultural schema in inferential and literal comprehension in L2 reading, System, 34.

[4] Anderson, R. C., R.E. Reynolds, D.L. Schallert and E.T.Goetz (1977), Frameworksforcomprehending discourse, American Educational Research Journal 14, (4).

[5] Anderson, R. C., \& Pearson, P. D. (1984), A schema-theoretic view of basic processes in reading, In P.D. Pearson, R.Barr, M.L.Kamil, \& P. Moseenthal (Eds.), Handbook of reading research. White Plains, NY: Longman.

[6] BahmanBeigi,M. (1989), Aal fromBokhara-ye man, Iile-man,Tehran: Agah Press.(Unpublished translation of the short story by the author of the study).
[7] Bartlett, F.C. (1932), Remembering: A study in EperimentalandSocialPsychology.Cambridge: Cambridge University Press.

[8] Bransford, J.D. and M.K. Johnson (1973), Considerations of some problems ofcomprehension. In W.G. Chase (ed.), Visual Information Processing. New York: Academic Press.

[9] Brantmeier, C. (2004), Building a comprehensive theory of adult foreign language reading: Avariety of variables and researchmethods, The Southern Journal of Linguistics, 27.

[10] Brewer, W. (2000), Bartlett's concept of the schema and its impact on theories of knowledgerepresentation in contemporary cognitive psychology, In A. Saito (Ed.) Bartlett, culture and cognition. Psychology Press.

[11] Carrell, P. L. (1983a), Three components of background knowledge in readingcomprehension, Language Learning 33, (2).

[12] Carrell, P. L. (1983b), Background knowledge in second language comprehension, Language Learning and Communication 2, (1/2)

[13] Carrell, P. L. (1983c), Some issues in studying the role of schemata, or backgroundknowledge, in second language comprehension, Reading in a Foreign Language, 1.

[14] Carrell, P.L. and B. Wallace, (1983), Background knowledge: context and familiarity inreading comprehension, In M. Clarke and J.Handscombe (eds.), On TESOL'82: Pacific Perspectives on Languge Learning and Teaching. Washington, DC: TESOL.

[15] Carrell, P.L., Eisterhold, J.C. (1983), Schema theory and ESL reading, TESOL Quarterly 17.

[16] Carrell, P. L. (1981a), The role of schemata in L2 comprehension, Paper presented at the 1981 TESOL convention, Detroit, Michigan.

[17] Carrell, P. L. (1981b), Culture-specificschemata in L2 comprehension, In R.A. Orem and J.F.Haskell (eds.), Selected Papers from the Ninth Illinois TESOL/BE. Annual Convention and the First Midwest TESOL Conference. Chicago: Illinois TESOL/BE.

[18] Chambliss, M.J. \& Call fee, R. O. (1998), Textbook for learning: nurturing children's mind, Blackwell publishers $1 \mathrm{td}$.

[19] Erten, I.H. (1988), Vocabulary learning strategies: an investigation into the effect of perceptual learning styles and modality of wordpresentation on the use of vocabularylearning strategies, Unpublished $\mathrm{PhD}$ thesis. Exeter: University of Exeter.

[20] Erten, I. H., \&Razi, S. (2009), Theeffects of cultural schema on reading comprehension,

[21] Reading in a Foreign Language, 21.

[22] Holland, D. \& Quinn, N. (Eds.) (1987), Cultural models in language andthought, Cambridge: Cambridge University Press. Cambridge: Cambridge University Press.

[23] Hudson, T. (1982), The effects of induced schemata on the "short circuit" in L2 reading: non-decoding factors in L2 reading performance, Language Learning 32, (1).

[24] Johnson, P. (1981),Effectson reading comprehension of language complexity and culturalbackground of a text, 
TESOL quarterly $15,(2)$.

[25] Johnson, P. (1982),Effects on reading comprehension of building background knowledge, TESOL quarterly 16, (4).

[26] Kant, I. (1781/1963),Critique of Pure Reason, London: MacMillan. ( $1^{\text {st }}$ edition $1781,2^{\text {nd }}$ edition 1787 , translated by N. Kemp Smith).

[27] Karakaş, M. (2005), The effects of pre-reading activities on ELT trainee teachers'comprehension of short stories, Journal of Theoryand Practice in Education, 1.

[28] Ketchum, E. M. (2006), The cultural baggage of second language reading: An approach tounderstanding, Foreign LanguageAnnals, 39.

[29] Kintsch, W. and E. Greene (1978), The role of culture-specific schemata in thecomprehension and recall of stories, Discourse processes 1, (1).

[30] Koda, K. (2005),Insights into second language reading: A cross-linguistic approach, NY: Cambridge University Press.

[31] Mandler, J.M. and N.S. Johnson (1977), Remembrance of things parsed: story structure andRecall, Cognitive Psychology 9,(1).

[32] McVee, M. B., Dunsmore, K., \&Gavelek, J. R. (2005), Schema theory revisited, Review of Educational Research, 75(4).

[33] Palmer, G.B. (1996), Toward a theory of cultural linguistics, Austin: University of Texas Press.

[34] Razı, S. (2005), A fresh look at the evaluation of ordering tasks in reading comprehension: Weighted marking protocol, TheReading Matrix, 5 (1).

[35] Rumelhart, D. E. (1980), Schemata: thebuilding blocks of cognition, In Theoretical issues in reading comprehension,ed. by R. J. Spiro, B. C. Bruce, and W. F. Brewer. Erlbaum.

[36] Rumelhart, D.E. and A. Otorny (1977), The representation of knowledge in memory, In R.C.Anderson, R.J. Spiro and W.E. Montague (eds.), Hillsdale, NJ:Lawrence Erlbaum Associates.

[37] Satio, A. (2000), Bartlett, culture and cognition, London: Psychology press.

[38] Sharifian, F. (2003), On cultural conceptualizations, Journal of Cognition and Culture, 3(3).

[39] Singer, M. (1994), Discourse inference processes, In: Gernsbacher, M.A. (Ed.), Handbook of Psycholinguistics. Academic Press,San Diego, CA.

[40] Strauss, C. \& Quinn N. (1997), A cognitive theory of cultural meaning,Strauss (Eds), Human motives and cultural models. Cambridge: Cambridge University Press.

[41] Thorndyke, P.W. (1977), Cognitive structures in comprehension and memory of narrativediscourse, Cognitive Psychology 9,(1).

[42] Yang, Y. (2008), The effect of cultural schemata on reading processing, In M.S. Plakhotnik\& S.M. Nielsen (Eds.), proceedings of the the Seventh Annual College of Education Research Conference: Urban and International Education Section. Miami: Florida International University.. 